\title{
Elements of Complementary Reflection as a Philosophy of Integration
}

\author{
Kidzu T. Oweh (Ph.D) \\ Department of Political Science and Public Administration, Adamawa State University, Mubi - Nigeria
}

\begin{abstract}
The essay captures those Elements of Complementary Reflection as utility principles in a complementary society that can serve the purpose of a philosophy of integration using the instruments provided by its own framework as paradigms for a universal understanding within the African Milieu. It discusses the dynamics of change within, which we can have as individuals should we maintain as human beings full of potentials to become what we ought to be, in a complementary framework, of a complex whole void of all existential illusion characterizing all human beings; ours' being the cheapest and weakest of all. Thus, elements of complementary reflection in Asouzu's socio-philosophic label are models which this discussion centres on as possible instruments of transformation which can solve the problems inherent in all negative values of the human nature in a human society. In doing this, the essay reflects on the nature of complementary reflection and how the elements can serve as philosophy of integration in and beyond African philosophy. In other words, complementary reflection as a philosophy of integration can help in solving the problems of human artificial divide and differences through the integrative elements elevated as paradigms of complementariness.
\end{abstract}

Keywords: Philosophy, Complementary Reflection, Integration, Asouzu, Africa.

\subsection{The Nature of Complementary Reflection}

\section{Introduction}

Now, to complement means an ability to add something to another in order to improve it or make that which is being added to, more attractive. Thus, for anything to become complementary, it takes or demands the putting together of things, though having different forms, yet are made to become attractive of each other and useful too. In this case, none works without the other. Complementary reflection thus engages itself as a carefully well thought out and written form of explanations and analysis about the non-monopolistic nature of human knowledge within a complementary whole. In other words, complementary reflection is an existential attitude of the human nature where no single person has the monopoly of knowledge but, as a unit, each complementing the ideas of the other in a whole universal system.

Asouzu, in The Method and Principles of Complementary Reflection in and beyond African Philosophy, projected that there are many logics. But all logics must be subdued to truth and authenticity. In this case, the essence of logic is to give a legitimacy of what we consider to be true. Since men are either posed to the relative or absolute pole in life, there is a tendency towards this or that way. The basis therefore which logic comes in is to open a criterion of truth (213). This criterion of truth by an application of a complementary logic as an explicative index reveals the whole foundation on which complementary reflection rest. The foundation is such that reflection is done from a holistic perspective in a universal context within an African milieu. Acceptably, ideas cannot be said to be one culture's exclusive prerogative, Asouzu opined (69). It follows therefore that men at opposite ends duly need themselves mutually for their interest to be realized. In this direction, we can see why complementary reflection addresses those fundamental philosophical problems to see how the different cultures of the world can solve their problems via an acknowledgement of each peoples' exclusive ignorance about the other's culture and epistemic rationality. To this extent, humanity becomes properly adapted to other cultures outside ones' own'. And this invariably helps us to see how we can have global harmony as a fundamentally new form of our human consciousness in the global trends of paradoxes. This is the gospel, which these elements of Asouzu's complementary reflection discuss and preach. The same is true. Similarly, we have chosen in this essay to highlight on these elements as utility principles in a complementary society that can grant the purpose of a philosophy of integration. It carries within its own body instruments that act as paradigms for such universal understanding of the African environment, peoples, culture and philosophy, with an understanding that rationality is a matter of degrees.

What then are those elements that can serve as integrative philosophy either within African, American, Asian, European or Western cultures? To answer the question we will first look at how complementary reflection and philosophy stand so as to explicate the elements and their integrative role. This is our focus and statement of problem to explain how complementary reflection can be integrative philosophy. 


\section{Complementary Reflection and Philosophy}

If we take philosophy to mean everything and all things, we would be accepting too many things without their links. But to say what the obvious is with philosophy in just one stroke of a statement can equally be an over assumption of thought without a careful critical approach. Philosophy, in its precinct looked out for answers to problems that can stand the test of time in both natural and human life universally. That is why from the point of view of Western Ideological boundaries and cleavages it is conceived as love of wisdom, taken from an understanding of their cultural background in an attempt to know what is in reality and what reality is. And so, from their points of view, and for early Greek philosophers from Thales to Aristotle, it became a science of the comprehensiveness of reality in a universal manner within a given cultural and historical setting. In the medieval period, it became a partner of theology where human society was viewed in terms of interior spiritual results, quite different from the principles of philosophy (Ogbuejiofor, 75-76). In the modern period philosophy took to the rational and empirical approaches where philosophers lined up according to their currents of thought. While the rationalists held on to the position of the rational is real and the real is rational, which gives them confidence in the power of human reason to understand reality, the empiricists on their part, took to the more practical approach of doing philosophy based on human experience and interpretation of reality. So philosophy thrived like that from Augustine to Aquinas, Erasmus and Luther to Montaigne; from Bacon to Leibniz; and from Locke to Hume; from Rousseau to Mill etcetera.

Contemporary philosophy has its bearing from Nietzsche to Marx, all of the Western culture. But what about contemporary African philosophy and its philosophers granted the fact as Asouzu opined that 'complementarism' is founded on the ambience of traditional African philosophy? (41). In my thinking, if there was an African philosophy of the traditional or ancient pattern, then there ought to be a contemporary one also, taking off from what was left undone. By now, we have become aware that ideas originate from people based on how they erect their lives and societies upon their action derived from their cherished values and concerns. Philosophy therefore in such context, is seen as what Asouzu called "an attempt at delineating perceived way of life or world view of a people ...philosophy is brought in close affinity with culture" (42). This being thus correct, 'complementarism', unlike Aristotle's metaphysics or Plato's idealism, Kant's transcendentalism or Hegel's absolute mind etcetera, pursues philosophy critically from an African background based on those ideas of the anonymous traditional African thinkers. The task of complementation is reached from Asouzu's reflection in this context, and reaching out beyond the African Milieu, rising above constraints of the diverse forms of personal or individual subjectivity towards a universal and comprehensive manner.

Philosophy of this complementary nature becomes such fundamental normative science that embarks on the task of addressing those ends of human action towards understanding, explaining and projecting deep answers into the causes of such action. In doing so, it reached out formulating principles and methods (as we shall see in its very elements) towards addressing the actions adequately. It equally analyses all the various interests guiding human action in a universally-minded attempt, saying how and why men can be in conflict with each other and how they can resolve such. Asouzu explicated further that in this way philosophy influences all harmonious coexistence of people in society through enquiries, upholding its self-understanding as wisdom by understanding reality truthfully and authentically (35). The fact that philosophy faces a great deal of challenges cannot be overemphasized. Challenges ranging from social and political matters, to economic, religious, ethical or moral, spiritual, scientific, metaphysical, physiological, psychological, epistemological, as well as anthropological etcetera. This covers a wide range of issues and activities involving human action in society.

Rising above these challenges, Asouzu proffers that philosophy should refuse the epistemological aesthetics of taking sides with politicized matters of ideological thinking, otherwise, philosophy will be seen as something turned inside out, as an implicit defence of some congealed contents highly prejudiced and packaged by some old philosophers in golden language just to impress their desired audience. What they do is to distort reality by transcending it in favour of their bias and tilt towards their subjective blindness against authentic understanding of the essential ontological understanding of reality. Philosophy done in this regard will be likened to Plato's vicious persons who engage in vice with an in-genuine ultimate aim of gaining happiness thus ignorantly from their vicious actions. This is what Asouzu rejects implicitly, saying that Aristotle (whom he said engaged himself in polarizing philosophy), with Locke, Hegel, Hume and Kant encompassing what is done in that category. These he called persons engaged in "folk mythological racial ideas" who are designed to ridicule and sensationalize. In this respect, Africa has to be useful to philosophy if philosophy has to be useful to Africa. What we mean here is that we cannot continue this way to the monolithic Western tradition of philosophy for Africa. What then must be done? Are we saying here that philosophy should turn revolutionary? Revolutionary of course, not of war but of harmonious intellectual decolonization; such is the case as we can see that the whole enterprise is being meta-positioned into an exercise of breaking away from one traditional stance to another. A matter of change which indeed must have inspired Heraclitus to hold out the opinion that all things are in flux, only change is permanent. It involves a clearing away of the rubbish in the way of knowledge for a repositioning of newer claims about knowledge acquired in every particular approach of human endeavour. That is why Mario 
Unterstainer's The Sophists translated from the Italian by Kathleen Freeman, stated that "man is continually being renewed, without being himself', trying to mirror the ultimate essence of things as found from the Heraclitian philosophy. In this regard, they called such a change "dissolution" which for them dissolves:

Human experience into a multiplicity of values revealed, or painfully experienced in the domain of inner consciousness; there is gradually emphasized the contradiction between the traditions, usages and customs of different peoples which by mutual comparison lose their universality in the contingent nature of chance or occasion (21).

Rising above such contradiction and painful experience occasioned by our human shortcomings in an attempt to understand different peoples of the world, Asouzu says, philosophy vis-à-vis the philosopher has an enormity of transcending all biases of secular thinking, private thinking and ideas that are prevalent, guided by an objective epistemic immunity to move ahead of this private subjectivity onto a higher and balanced plane of unprejudiced theory formulation of reality (45) Perhaps this is why he echoed in Effective Leadership and the Ambivalence of Human Interest that unless men have learned to place the common good above their private interests it will remain difficult for us humanity trying to proceed to manage our affairs (13).

The question one may ask is what makes this philosophy of his complementary?

2.2.1 It is complementary because it recognizes relative existences.

2.2.2 It also sees all relative realities as a moment of what he termed the transcendent unity of consciousness, seeking expression diversely in history.

2.2.3 It is complementary because it also seeks to understand the need to relate all relative entities towards a common foundation of meaning and authenticity in a universal and all embracive way.

2.2.4 It is complementary because one sees in it the inclusion of the spirit of world-multipolarism.

2.2.5 It is complementary because it undertakes to understudy reality by rightful application of concepts, by an explication of their meaning in a manner that relates accurately, and designates and captures mutual relativity of life.

Summarily, Asouzu upholds the view that complementary reflection is an inquiry into the nature, essence and substance of being in such a precise, universally complete and comprehensive way. It is a methodology amongst many competing methodologies, but neither transcendental in constitution or in application. It is rather transcendent (43). This issue of non-transcendental but transcendent will raise some criticism in our later part of this essay. This, with other pertinent issues which he contradicted some cultural configurations about African philosophy will need some clarification. Notwithstanding such opposition, he opined that complementary reflection has its roots in the background of traditional African philosophy as a model which seeks universal relevance following the collapse of hitherto ideological blocks of the Old World Order (41). This philosophy from the ambience of African traditional philosophy seek to be comprehensive and universal in orientation from the way it sees reality; systematically communicating it while relying on new facts and insights away from the old that are peculiar both to the African or Western, European or Asian ontologies. Having done with some excursion in literature review as such, let us go over to those elements of complementary reflection to see how they can serve the purpose of a philosophy of integration.

\section{Elements of Complementary Reflection.}

There are some things in any given mode of human existence which are necessary for social cohesion, their absence which would pose serious threats to any group. Elements of complementary reflection on their part stand out as those models in philosophy which are capable of mediating between our human ambivalent situations and interest positively, against the severe passionate approach to our self-destruction occasioned by such ambivalence. Some of these integrative elements of complementary reflection include: Absence of artificial barriers, intricate mutual services, mutual coherence, commitment to unity, wholesomeness of purpose, openness to the future, harmony of differences and interest, etcetera.

Complementary reflection captures the images of these elements as framework of unity for progressive philosophizing in a complementary whole, for the processing and making of its image as a philosophical model that allows space for other philosophies to thrive. In other words, flexibility as one of the elements is geared towards overcoming all intrinsic negative tendencies which our human ambivalent interest can cause as barrier to progressive integrativeness in philosophy.

Complementary reflection offers these elements as principles for a universally comprehensive platform of knowledge enquiry, acquisition, exposition and impartation. They act as anodyne of social cohesion and cohesiveness. Such anodynic nature of Asouzu's elements has prototype in Confucius' element of 'Li' in Chinese philosophy translated as "the order of things", "propriety" (including moral and social behaviours or rules of correct and proper conduct), "courtesy", "ritual", ceremony and reverence" etc. These element, Confucius' philosophy gave as those which will guide society and its human ambivalent character which have turned Chinese society of his days negatively, which they need to go back to the ancestral heritage of cherished values and goals. Asked what this element 'Li' signifies, Confucius responded: 
Of all the things that people live by, $\mathrm{Li}$ is the greatest. Without $\mathrm{Li}$, we do not know how to conduct a proper worship of the spirits of the universe, or how to establish the proper status of the king and minister.., rulers and the ruled, elders and the juniors; or how to establish moral relationship between the sexes,.. parents... children... and.. others; (Watch Tower, 180).

What we try to link between Asouzu's elements of complementary reflection and Confucius' 'Li' is to bring out the issues of mutual interaction and absence of artificial barriers which Asouzu say should guide human rationality to universal standard where philosophy will seize to be the claim of one cultural group characteristic as is found in Western philosophical tradition.

Granted that "men at opposite ends need themselves mutually for their interest to be realized' the idea of harmony of differences is a key elemental function of the complementary principle within an intrinsic complementary relationship in the complementary - whole - framework of this integrative drive of philosophy. In other words, complementary reflection captures this image of the framework of units within a complementary whole as a ground consideration of Ozumba's globalized human being seen from the point of view of human universality; exhibiting no ethnic, racial or geographical limitations and boundaries and cleavages (7). A forward looking philosophy in Africa, of Africans, written in a complementary action of the universal standpoint. To make for such universally overwhelming integration of African philosophy, one hears Asouzu and Ozumba, in their separate tones and postulations say the categories of tolerance, endurance, forgiveness and acceptance become our paradigm for pursuing a new cause for African philosophy which is complementary in this nature (Asouzu, 77) and (Ozumba, 1-14). The hitherto poor attitude of lamentation and spirit of unforgiveness should not continue to stare us in the face, begging for action. One can infer why, and now understand how communalism as an element in this complementary reflection which Asouzu says has its roots planted in the soil of African complementary system of thought, is never a complex as some may have thought, of human societal abuse, but, the foundation on whose blocks the elements of complementary reflection with its 'spirit' of tolerance', allow the categories to operate.

These elements pursue philosophy with a heart and spirit of relationship. Such is it as Ambassador M. B. Ekpang in his "foreword" to Oshita's Towards self-knowledge: Essays in the Boki Nation opined:

The $21^{\text {st }}$ century would be increasingly driven by knowledge and a constellation of high technology information systems. This fact challenges every human group to justify its occupation of a portion of the global space by making its own contributions to world knowledge. Communities that benefit from the global knowledge pool have a duty to also put something back into the pool from which they benefit (vi).

A denial of the services of the spirit of relationship as seen in the justification of knowledge occupation of every group in the global space, invariably and inadvertently becomes a disservice to oneself. A disservice which Asouzu says is caused by the activities of the human mind. The mind, being placed under this illusion sees nothing good of the other self but itself.

The mind creates what is termed 'advantages for its own survival; an interest created out of its own cognitive self; worked out of its ambivalence and perceiving the world in such a simultaneous mode of the positive and negative parts; the negative most often, overweighing the positive (65).

The elements of complementary reflection call for a consistent commitment to the principles of complementary reflection in order to awaken the cognitive consciousness of all stakeholders in any system of philosophizing for a better understanding of how to manage and cope with our human ambivalence and complex situations. Taking for instance the issue of interest as an element, it is realized that an individual is a missing link to another individual who also is a missing link to another as a unit, in a system of a complex whole, who can serve the interest of the other by exchange of one's own interest through a 'let-go' paradigm which in this case, is Asouzu's call to a higher principle of a higher rationality swung up, and far removed from such semi-rational instinct often occasioning us to seek our self-preservation. One therefore becomes a found link based on the realization of these elements, their absence which have produced the very shortcomings we have in our nature of doing philosophy. In this regard, we can operate favourably in conjunction with such realization that one philosophy becomes a missing link of the opposite other within the whole system. No wonder Asouzu says "moments of complementary mutual relationship is missing in Western philosophy".

Indeed, between Bentham and Mill, we see in their philosophies, utilitarian elements of philosophy based on moral motives, sociability, feeling of universal altruism, sympathy and justice, which they pursued at different levels. There exists a universal spirit of their coinage 'utilitarianism' following what is derived from these elements. Their utilitarianism may serve as panacea in western philosophy. Our inference to this utilitarian mode of Bentham and Mill draws global concern of which philosophy, as pursued by Asouzu in this complementary nature impinges on the tenets of globalization (Mukherjee and Ramaswamy, 321-330). In fact, one observed how these elements of complementary reflection (which I have found to be utilitarian in African philosophy) could affect the whole wave of social institutions. Just as vehicles need roads for their plying, so does philosophy need these elements to cruise along together. Let us now take some appraisal to see how we can 
arrive at a conclusion of these elements as instruments of transformation for an integrative philosophy in and beyond African philosophy.

\section{Appraisal and Conclusion}

Social experiences have shown that certain amount of change in knowledge application would force society not to remain the same. This is so because one knowledge acquisition and application in one context can find application in another when such societies come in contact with such new knowledge in vogue. Ideas, norms and institutions spread from one society to another. This is what Asouzu's elements of complementary reflection stand for. They call for an adjustment to certain knowledge condition that found their base on elitism. By elitism here we mean doing philosophy in a non-complementary manner as most Western and African philosophers have done. But are we now saying philosophy is starting a new beginning with Asouzu and no other one? No. It may not be the case. A leap into a kind of universal knowledge application of the complementary nature which Asouzu called higher principle and transcendent but not transcendental becomes his point of departure to build a philosophical world and mind-set that is all embracive and could advance knowledge for world peace in the New World Order.

This therefore is to say that the elements of this philosophy are performing some social functions as justified moral umpire of global peace and harmony in the area of knowledge-drive by the institutionalization of philosophic justice in knowledge, where sound wisdom takes precedence over all other human attractions and merchants of ideas.

We may still ask for a better understanding that, what is the nature or essence of this higher principle whose elements Asouzu found to be the ontological status of complementation? What legitimizing role do they play? And how equally is this legitimizing role legitimate for a general acceptance by all? Asouzu half way and indirectly says, they are necessary links which have their roots in equity and justice. That they are ingredients that could add to the making of the realization of the interest of the whole other than units of the whole. He then calls for an application of these elements by men in quest of knowledge drive in the legislation of matters rather than seek function to themselves in doing philosophy. The general interest of all is his driving motive. A rejection of these targets or goals by actors in the play off of knowledge from the units can adversely affect the whole in our global drive for world peace and harmony.

But, do we not consider in our thinking as in the case at hand with Asouzu's thought that our human shortsightedness is being unwittingly played upon by this faulty part of human consciousness, that we so tried to consider the whole in preference, and subsequently neglecting the very concern for the units in a complementary way as this, that equally often add more tension to the already created ones? Is this not part of the picture Asouzu himself has created in trying to place this philosophy in some carved out pedestal? Our academic quarrel here with this erudite professor of philosophy is, how do we know that this higher principle of integration is capable of guaranteeing the equitable participation of all that are involved? Is there any rudimentary logic that could guarantee truth that human beings could actually in future overcome this ambivalence of the human nature?

Granted that the human mind itself falls short of the nature of being universal in its operational frequency; granted that we have different and several levels of such frequency of operation, how then, or what is the guarantee that abiding by these elements of this higher principle will loosen and set aground the strings that tie human ambivalence and interest? For we know that the only and one universal mind that can be without errors is, as Asouzu opined, the mind of God, which has no polarizing entity. If it were not so, how would Asouzu have had such intellectual quarrel with Aristotle's polarization of philosophy?

In attaining his object, Asouzu, said these elements of this higher principle are the reason for most traditional African's ability to surmounting their problems. And that success for them arise as a result of their recourse to the principle and had beeli admired as the fulcrum around which the traditional African spirit of universal brotherhood and communalism are known for. is this higher principle integrative at all? If the case be true, how can Asouzu reconcile his other thesis that the same principle of communalism is not an African heritage while he tried to use it as an ingredient in building complementarity in African philosophy?

Asouzu in further complementation of this project says is an attempt at reformulating and expounding of the principles of complementarity concretely built as a guide or pointer to the transformation of our human ambivalent actions towards a maxim that becomes a general law. Does this give us an ethic of the kind of Kant's categorical imperative or not? Or is it a new framework of building a universal ethical maxim based on his selfacclaimed integrative complementary principles? What are the limitations of these maxims which become the task of his work? Where can we find the imperatives advantageous enough to address these matters? How are these principles of his transcendent and not transcendental? The difficulties in finding solution to these questions will continue because of suspected ideological boundaries that inherently overweigh the human mind due to our refusal to submit willingly to the spirit of openness.

Let us believe that this is one system among many that is groomed with some scientific interest. According to Nwaigbo, the characteristics or features of science are that it is empirical, verifiable and scientifically 
demonstrable of facts and data (17). This being so with science as the basis now from which world politics is played, we would ask one more question whether this category of Asouzu's approach to philosophy can go beyond the context of these scientific characteristics to demonstrate itself as one instrumental philosophical element ready to place itself on the corridors of science necessary for global politics and peace? This, and other previous questions raised before become our point of departure in response to Asouzu's elements of complementary reflection as a philosophy of integration. They require answers upon reflection. This is a task in philosophy and a standard for philosophical inquiry if philosophy must remain the queen of the sciences and art.

\section{Conclusion}

In conclusion, it is our desire that these elements of complementary reflection, being guided by some internal instruments become paradigm for world peace where wisdom everywhere stands as wisdom and individuals and nations contribute to the universal pool. In other words, Aristotle's wise man must allow himself to be persuaded by sound knowledge rather than the idea of his refusal to be ordered, or caused to obey, but must cause those he feels are unwise to be ordered and obey him. Elements of complementary reflection seek a plane where all wise men will cohabit with the unwise, and all supposedly unwise people will learn to become wise in a spirit of tolerance for global peace. That is why I think this higher principle is complementary indeed.

\section{References}

[1]. Asouzu, I. I. (2004). The Method and Principles of Complementary Reflection in and beyond African Philosophy. Nigeria: University of Calabar Press.

[2]. Asouzu, I. I. (2003). Effective Leadership and the Ambivalence of Human Interest: The Nigerian Paradox in a Complementary Perspective. Nigeria: University of Calabar Press.

[3]. Asouzu, I. I. (2006). "Re-ethnicizing the Minds? Culture Revival in Contemporary Thought". Ed. Thorsten Botz-Bornstein Jurgen Hengelbrock, Canada: www.rodopi.nl/2006.

[4]. Ekpang M. B. (2004). "Foreword" Towards Self-Essays on the Boki Nation 1 Ed. Oshita O. Oshita. Ibadan: Hope Publications.

[5]. Mukherjee, S. and Ramaswamy, S. A. (2005). History of Political Thought: Plato to Marx. New Delhi: Prentice Hall of India.

[6]. Nwaigbo, F. (2002). "Scientific Ideologies at the Dawn of a New Age" Global Journal of Humanities vol.1 No.1. 13-23

[7]. Oguejiofor, .J. O. (2001). Philosophy and the African Predicament. Nigeria: Hope Publications.

[8]. Ozumba, G. O. (2004). Ed. "African Metaphysics" A Colloquium on African Philosophy. vol.2. 1-14. Calabar: Jochrsam Publishers.

[9]. Ozumba, G. O. (2003).Ed. "The Spirit of Contemporary African Philosophy" A Colloquium on African Philosophy vol.1. 7. Calabar: Jochrisam Publishers.

[10]. Untersteiner, M. (1954). The Sophists (Translated By Kathleen Freeman). New York: Philosophical Library.

[11]. Watch Tower, (1990). Mankind Search for God. Pennsylvania Watch-tower Bible and Tract Society. 